\title{
LA BIBLIOTECA DEL COLEGIO DE SAN GREGORIO: ¿UN ACERVO PARA INFANTES INDÍGENAS CATECÚMENOS?
}

\section{THE LIBRARY OF THE COLEGIO DE SAN GREGORIO: A COLLECTION FOR INDIGENOUS CATECHUMENS?}

\author{
Arturo Soberón Mora \\ Instituto Nacional de Antropología e Historia \\ Dirección de Estudios Históricos \\ sobemora@gmail.com
}

\section{Resumen}

Fundado a inicios del siglo XVII por los jesuitas para la instrucción religiosa, las primeras letras y la música de los hijos de los indios caciques de los alrededores de la ciudad de México, el Colegio de San Gregorio muy pronto se convirtió para los religiosos en centro de aprendizaje y práctica de las lenguas indígenas. En este trabajo se explora en qué medida las dos bibliotecas con que contó el plantel fueron instrumento activo de esa labor lingüística.

Palabras clave: colegios, indios, lenguas, expulsión de jesuitas.

\begin{abstract}
Founded at the beginning of the 17th century by the Jesuits, for religious instruction, first letters and music of the sons of the caciques Indians, the College of San Gregorio soon became a center for learning and practicing native languages. This paper explores to what extent the two libraries on the campus were an active tool in this linguistic work.
\end{abstract}

Keywords: colleges, Indians, languages, expultion of the Jesuits.

\section{Información del artículo}

Recibido: 17 de julio de 2018.

Aceptado: 26 de noviembre de 2018.

DOI: 10.22201/iih.24486922e.2019.61.65584 
En junio de 1767, el virrey marqués de Croix ejecutó en tierras novohispanas la orden de Carlos III de expulsar de los territorios españoles a los miembros de la Compañía de Jesús. Acto seguido, los oficiales reales procedieron a formar un inventario meticuloso de los bienes existentes en cada uno de los establecimientos que ocupaban los ignacianos (templos, colegios, haciendas, ranchos, trapiches y misiones, entre otros) con el fin de llevar un control de su género y volumen y prepararlos para su posterior remate o reubicación.

Una de las instituciones inventariadas en ese sonado episodio fue el Colegio de San Gregorio. Los registros elaborados por los funcionarios reales mostraron que el templo del Colegio contenía una gran riqueza ornamental, pues estaba colmado de piezas de orfebrería trabajadas en oro y plata y engastadas de piedras preciosas. Pero igualmente, en forma paralela, los inventarios de la biblioteca anexa, que incluyen los aposentos de los religiosos que estaban al frente del colegio, revelaron otro resultado que llama poderosamente la atención: se trataba de centenas de libros referentes a teología, patrística, sermones, vidas de santos, pero sobre todo de impresos y manuscritos referentes al dominio, aprendizaje y enseñanza de lenguas indígenas. San Gregorio era en el momento de la expulsión de los miembros de la orden un colegio que albergaba apenas dos docenas de niños indios, a los que tres o cuatro jesuitas residentes les tutelaban una enseñanza básica. Al revisar los contenidos de la biblioteca, da la impresión de que éstos no tenían demasiado que ver con las necesidades de los párvulos y que incluso rebasaban las que podían demandar para su ejercicio los docentes. San Gregorio estaba físicamente ubicado adyacente a las instalaciones del Colegio Mayor de San Pedro y San Pablo y por esa razón podría pensarse que su biblioteca y la riqueza de la misma contribuía a las labores del segundo. Sin embargo, San Pedro y San Pablo contaba igualmente con una importante y especializada biblioteca, ajustada a las necesidades del colegio; por lo tanto, parece improbable que la de San Gregorio hubiese sido creada con el fin de estar vinculada a la del Colegio Mayor. ${ }^{1}$ Por otra parte, desde finales del siglo Xvir se había cerrado la comunicación entre

${ }^{1}$ Comparativamente la biblioteca de San Pedro y San Pablo era, por lo demás, cuantitativamente muy superior a la de San Gregorio; sus casi veinte mil volúmenes la convertían en la más importante de América en ese periodo y su perfil temático abarcaba un amplio horizonte cultural que comprendía a todos los clásicos grecolatinos, a los humanistas del Renacimiento, las obras teológicas en sus diversas corrientes y temas, literatura hermética, castellana, etcétera. Véase Osorio Romero (1986, pp. 67-74). 
los dos colegios y para mediados del siglo XVIII no hay indicios documentales que sugieran un tránsito libre de pupilos o docentes entre San Gregorio y San Pedro y San Pablo. ¿ ¿Por qué, entonces, la presencia en San Gregorio de una biblioteca que parecía responder a fines aparentemente desvinculados de su labor docente?

En las siguientes páginas intentaremos demostrar que San Gregorio, en respuesta a los propósitos misionales de la Compañía de Jesús, convirtió el plantel en una suerte de estación de paso para los religiosos que, en vísperas de marchar a las misiones del norte, requerían para su ejercicio de un dominio eficiente de las lenguas indígenas. La presencia misma y los contenidos de la biblioteca del colegio se ajustaban entonces a esos propósitos.

¿Libros para niños indios o para misioneros?

Desde su arribo a tierras novohispanas en 1571, los miembros de la Compañía de Jesús reprodujeron con pocas variantes la política que la Corona española había establecido desde los primeros años de colonización americana hacia la población indígena: centrar los esfuerzos catequísticos en la población nativa infantil. Los jesuitas, al igual que hicieron los franciscanos y dominicos en años precedentes, vieron en los hijos de la nobleza indígena el factor de penetración de largo alcance de las nuevas ideas religiosas, que asegurase que los portadores reprodujesen con éxito la extensión del adoctrinamiento en sus comunidades de origen.

En los primeros años de consolidación del reino, sin embargo, la Corona, en coincidencia con regulares franciscanos, ambicionó el proyecto de enseñar latín a los indios. En el contexto de la polémica sobre la racionalidad del indio, que deja zanjada la Bula de Paulo III a favor del indio, expedida en 1536, y que por lo tanto hasta ese año hacía improbable que se

${ }^{2}$ Desde las primeras décadas de su funcionamiento, y hasta el año de 1683, San Gregorio tuvo comunicación con San Pedro y San Pablo, debido a que San Gregorio no contaba con bienes para su mantenimiento y sus sacerdotes eran sustentados a costa del Colegio Mayor. Cfr. Astrain (1905-1925, t. 5, pp. 321-322). Pero a partir de la donación que hizo Juan Chavarría en dicho año de la hacienda de San José Acolman a San Gregorio, se cerró la comunicación. Biblioteca Nacional de Antropología e Historia (en adelante, BNAH), Colección Antigua, vol. 254, "Apuntes para la historia del Colegio de San Gregorio por Faustino Galicia Chimalpopoca”; también Alegre (1956, vol. II, pp. 622-623). Con todo Alegre, reporta que en 1609 se cerró el paso entre uno y otro colegio. 
pensase en la formación de un clero indígena, ese mismo año se lleva a cabo la fundación del Colegio para indios principales de Santiago Tlatelolco. ${ }^{3}$ Debido a la importancia que aparejó este acontecimiento, sobre todo en el terreno lingüístico y cultural, la historiografía reciente se ha ocupado de aportar nuevos datos y enfoques. Enrique González González, además de encuadrar la fundación de Tlatelolco en un pretendido intento de la Corona -no única ni exclusivamente franciscano- por introducir la enseñanza del latín a hijos de indios caciques, contribuye con la información necesaria para ver en las gestiones del oidor Sebastián Ramírez de Fuenleal (1490-1547) un empeño definitivo en esa dirección. ${ }^{4}$ A pesar de que se puede considerar relativamente temprana la cancelación del proyecto de Tlatelolco, fray Bernardino de Sahagún (1499-1590) desarrolló en su seno un afanoso proyecto lingüístico que permitió, entre otras cosas, la fijación gramatical del náhuatl, así como la formación de "artes” y vocabularios de otras lenguas nativas que, en su conjunto, servirían de plataforma para que los jesuitas llevasen a cabo más adelante un ambicioso proyecto misional.

En el año en que los miembros de la Compañía de Jesús arriban a la Nueva España (1571) el Colegio de Tlatelolco se encuentra en un estado de avanzada decadencia - agobiado sobre todo por el retiro de la ayuda económica oficial, la disminución de la población indígena debido al azote de las epidemias y, sobre todo, a la reticencia de la Corona de formar indios gramáticos-. Ciertamente era una institución desfalleciente, pero a ojos de los ignacianos no escapó el valor del trabajo lingüístico logrado por Sahagún. Muy probablemente sin pretender emular a Tlatelolco y con las enormes diferencias de propósitos y alcances, en el año de 1589, llevaron a cabo la fundación en la ciudad de México de un colegio para la educación de los hijos de los indios caciques o "principales" bajo la denominación de San Gregorio. ${ }^{5}$

En este establecimiento los niños fueron catequizados bajo el sistema del internado, es decir, aislados de la influencia de sus padres y antiguos

${ }^{3}$ González González y Gutiérrez Rodríguez (2015, pp. 202 y 205).

${ }^{4}$ González González (2011, pp. 91-110). Igualmente somete a revisión la versión de Robert Ricard y sostenida por José María Kobayashi, de considerar a Tlatelolco como un intento fallido de formar un clero indígena.

${ }^{5}$ Como parte de una aplicación paralela de esos fines, en el año de 1618 por iniciativa del virrey Esquilache se fundó en Lima, Perú, el Colegio del Príncipe (conocido también como del Cercado) para hijos de indios caciques y dos años después Esquilache fundó en el Cuzco otro colegio de propósitos y estructura similar al primero, llamado de San Borja, ambos manejados por los miembros de la Compañía de Jesús. Para un análisis comparativo del funcionamiento del Colegio del Príncipe y el de San Gregorio, véase Soberón (2005, pp. 563-583). 
sacerdotes indígenas, con el fin de evitar que éstos pusiesen en duda en la mente de los infantes la validez del adoctrinamiento. Consumada su preparación y devueltos a sus comunidades de origen esos menores fungirían como efectivos agentes de apoyo a la labor evangelizadora que llevaban a cabo los misioneros regulares. En este proceso de catequesis de los párvulos nativos, los ignacianos aplicaron en el colegio un método que a los franciscanos había dado ya buenos resultados: la educación musical. Este recurso permitió, por partida doble, que los alumnos asimilasen con rapidez el adoctrinamiento religioso y que el coro y la banda de músicos en los que fueron integrados se proyectasen como imagen positiva del colegio hacia el amplio conjunto social. De tal forma, a lo largo de su existencia, San Gregorio contó con coro y banda de músicos integrados por niños indígenas, que eran contratados por casi todos los templos de la ciudad para acompañar los oficios religiosos. La decisión de perfeccionar a los niños en el campo musical, por otra parte, no parece del todo casual.

Si bien en los primeros años los jesuitas mostraron cierta simpatía con la vieja idea del clero indígena, muy pronto se plegaron a las reales disposiciones, entre las que se encontraban las conclusiones del Tercer Concilio Mexicano de $1585 .{ }^{6}$ En las fuentes documentales y bibliográficas consultadas para el caso del Colegio de San Gregorio, la posición registrada muy pronto quedó definida: la educación de los niños indígenas estará compuesta única y exclusivamente por la enseñanza de los principios religiosos, las primeras letras y una preparación musical esmerada; es decir, para los indios quedaba cancelada la posibilidad del ingreso a estudios superiores. Mucho se ha debatido recientemente sobre este punto de la educación indígena en la que autores como Margarita Menegus encarecieron el hecho de presentar numerosos testimonios acerca de las oportunidades de estudios universitarios que alcanzó cierto sector de la sociedad indígena, sobre todo en el siglo xviII. ${ }^{7}$ Sin embargo, como enfatiza Enrique González, "no se

6 "Para que se dé la orden clerical, el honor y reverencia que corresponde, está establecido por los sagrados cánones, que no sean ordenados los que padecen algunos defectos naturales, $\mathrm{u}$ otros, que aunque no se imputen a culpa, traen indecencia para el estado clerical; [...] De aquí es que tampoco deben ser admitidos a los órdenes sino los que cuidadosamente se elijan de entre los descendientes en primer grado de los nacidos de padre o madre negros, ni los mestizos, así de indios como de moros." Concilio III Provincial Mexicano, p. 56.

${ }^{7}$ Véase Menegus y Aguirre (2006). Sin embargo, confirma la posición de E. González: "De tal manera, los indígenas que se graduaron en la Real Universidad de México, por lo general provenían de este sector social [caciques] privilegiado. Como veremos a lo largo de este libro la mayoría de los estudiantes indígenas eran nobles", p. 16 (las cursivas son nuestras). 
pretendía que la formación universitaria llegara a toda la población. Era una instancia en favor de la casta europea. Sólo en casos excepcionales abrió sus puertas a los indios, siempre que fueran reconocidos como caciques". ${ }^{8}$ En casi todos los escritos y correspondencia jesuitas del periodo se enfatiza esta marcada posición hacia la educación de los alumnos del colegio, punto de vista que conviene tener presente en tanto que la catequesis, las primeras letras y la música no parecen haber sido los únicos motivos ni los prioritarios que animaron el funcionamiento de la institución durante el periodo virreinal, como veremos a continuación. ${ }^{9}$

En los años posteriores al inicio de su fundación, San Gregorio se fue transformando en algo más que un mero instituto de formación religiosa y musical básica de niños indios. En una suerte de inversión de propósitos, el colegio comienza a ser utilizado por los ignacianos como un centro de especialización lingüística, es decir, un plantel en donde los padres misioneros de la Compañía practicaban con los alumnos indígenas -incluido su entorno familiar y social agrupado en las cofradías asociadas al templo del colegio- el conocimiento de las lenguas indígenas que habían adquirido en sus propios colegios. Esto se entiende porque San Gregorio se saturaba cotidianamente por los sonidos del náhuatl, el otomí y el mazahua. Los padres de San Gregorio debían estar versados en esas lenguas, con el fin de cumplir, además, con la obligación ministerial de acudir a confesar a los indios de su demarcación, atender a los indios enfermos menores y mayores "y hacer otros ministerios concernientes a los indios". ${ }^{10} \mathrm{El}$ templo de Loreto - su primera fábrica era de tres naves- lucía pletórico de asistentes indígenas en cada una de las numerosas festividades que se celebraban a lo largo del año y se multiplicaban en adviento y cuaresma, todas con liturgia y sermones en lengua mexicana, acompañadas por representaciones que hacían los colegiales de coloquios de "materias de santos en su lengua."11

${ }^{8}$ González González (2015, p. 27).

${ }^{9}$ Se acepta que, desde finales del siglo XviI, las aulas de colegios y seminarios y aun de la Universidad permitieron ocasionalmente el ingreso de alumnos indígenas e, incluso avanzado el XVIII, se pensó en la posibilidad de formar un clero indígena, planteado en el proyecto de creación del Colegio de San Carlos Borromeo; sin embargo, la idea enfrentó la oposición, por una parte, del virrey Bucareli y la Dirección de Temporalidades, alegando fondos insuficientes y, por el otro, del clero novohispano. Véase Soberón Mora (2008, cap. IV). Para la oposición del clero novohispano al proyecto, véase Menegus (2004, pp. 283-301).

${ }^{10}$ Alegre (1956, vol. II, pp. 622-623).

${ }^{11}$ Pérez de Ribas (1992, pp. 736-737). 
San Gregorio como centro de aprendizaje y práctica de lenguas nativas con fines doctrinales

Según el padre Miguel Venegas, el colegio de San Gregorio era el destino frecuente de algunos jesuitas que estuviesen de regreso de las misiones norteñas o en espera de nuevos destinos. ${ }^{12}$ Esta selección al parecer no era totalmente casual. La presencia de los niños indígenas y lo que ello implicaba -alegría infantil, la cercanía de su canto, música y danza, pero sobre todo la oportunidad de repasar sin la inhibición, común en los adultos, aquellas dudas lingüísticas con las que retornaban de su periplo misionallos impulsaba a ver en San Gregorio el remanso activo que los prepararía para una eventual nueva jornada. ${ }^{13}$

Indudablemente, San Gregorio parecía representar el recinto ideal para la práctica de las lenguas nativas. La reunión permanente en el recinto de los niños indígenas facilitaba enormemente las posibilidades de practicar su lengua, método de reconocida eficacia practicado incluso en las misiones norteñas, como era el caso de las misiones sinaloenses en donde "allí ni había otro arte ni vocabulario, ni otro medio más a propósito para poderlas aprender, sino oír hablar a muchachos que venían a la iglesia". ${ }^{14}$ Su funcionamiento, sin embargo, era el resultado de varios ensayos hechos en años anteriores, en los que se buscó el procedimiento más viable para un cabal y perfecto aprendizaje de las lenguas indias dominantes. En esa intención los religiosos jesuitas probaron eficacia con dos modelos vigentes en sus fundaciones europeas, pero ajustado a las necesidades y contexto americano: el colegio y el seminario. El primero se ciñó al procedimiento de convocar a los niños indígenas a la escuela que para el efecto solían abrir los religiosos en la residencia local, con el fin de aprender de ellos su lengua materna y logrado el dominio

12 Venegas (1979). Es el caso del padre Juan María de Salvatierra, quien en 1707 preparó en San Gregorio su siguiente salida para la misión californiana de Loreto (vol. I, p. 199). Puede mencionarse igualmente el caso del padre Julio Ugarte, quien en 1710 parte de San Gregorio para las misiones de California. AGNM, Archivo Histórico de Hacienda, leg. 281-29.

${ }^{13} \mathrm{Al}$ respecto agrega Gerard Decorme: "Parece que por entonces era como una gloria entre los padres fervorosos cuidar de estos inditos, pues hallamos nada menos que a un gran teólogo, el p. Juan de Ledesma (tenido por un segundo Hortigosa y oráculo del reino) hacer siempre gran lugar a los ministerios de San Gregorio, cuyo templo renovó casi enteramente y cuidaba por sí mismo como el más humilde coadjutor”. Decorme (1941, vol. 1, p. 254).

${ }^{14}$ Los jesuitas y las lenguas indígenas... (1927, p. 104). 
enseñarles la doctrina cristiana; el segundo implicaba abrir, con un fin similar, un seminario de niños internados o convictorios en número por lo general reducido. La apertura del colegio de Pátzcuaro hacia 1577, ${ }^{15}$ responde al primer modelo, lo mismo que el colegio que los religiosos abrieron en el poblado de Huizquilucan en 1579, mientras que las posteriores fundaciones de los seminarios para hijos de indios caciques de San Martín en Tepotzotlán y de San Gregorio de México se ajustan al segundo. ${ }^{16}$ Cabe indicar que el colegio de Huizquilucan fue cerrado cuando los religiosos advirtieron más tarde la ventaja que representaba la región de Tepotzotlán, zona en la que, además de sus fértiles tierras y abundancia de agua, sus moradores eran hablantes de náhuatl, con una importante presencia también de las lenguas mazahua y otomí, y pareció, por lo tanto, lugar más propicio para fundar el colegio. Impulsados por estas razones fundan en ese sitio, en 1584, el Colegio-Seminario para hijos de indios caciques de San Martín, auspiciados por el Colegio Mayor y con la donación de tierras y dinero que para tal fin hizo a los miembros de la Compañía Martín Maldonado, cacique del pueblo. ${ }^{17}$

En años más o menos paralelos los ignacianos procedieron de manera muy similar en el Perú. Por ejemplo, los jesuitas que estudiaban en ese momento las lenguas indígenas quechua o aymara o ambas, acudían a la doctrina del Cercado en Lima para su práctica y una vez adquirida solían después perfeccionar su dominio en el seminario que la Compañía tenía en el Cuzco para hijos de indios caciques. ${ }^{18}$ Hacia 1600 los padres recién ordenados se entrenaban en el dominio de ambas lenguas en la doctrina de Juli en el Alto Perú. ${ }^{19}$ En 1696 se dispuso que la Tercera Probación se hiciese en la doctrina del Cercado. Hasta entonces la Tercera Probación "se hacía no sólo en las ciudades de Huamanga y Cuzco, sino también en Juli y aun en el mismo Cercado. La razón de haberse escogido estas dos

${ }^{15}$ Conviene señalar, a propósito del colegio de Pátzcuaro, que éste funcionaba igualmente como centro desde el cual los religiosos residentes en el mismo eran enviados a misiones a diferentes regiones del obispado, por periodos que generalmente no excedían de dos meses, pero prueban que estos colegios servían como punto de partida y financiamiento de ese tipo de políticas dentro de la Compañía. Véase Ramírez (1987, pp. 113-116).

${ }^{16}$ Zubillaga (1974, pp. 21, 28-30).

${ }_{17}^{17}$ Pérez Alonso (1988, pp. 80-89).

${ }^{18}$ Acosta (1954): Carta Anua que envía Acosta, como Provincial de la Compañía en Lima, al padre Everardo Mercuriano, General de la misma. Lima 15 de febrero de 1577, p. 264.

${ }^{19}$ Historia general de la Compañía de Jesús... (1944, vol. 1, p. 41). 
últimas casas era la de ser a propósito para el aprendizaje de la lengua de los indios". ${ }^{20}$

En suma y vistos los ejemplos señalados no extraña que los padres ignacianos viesen con particular predilección el Colegio de San Gregorio como sede de práctica lingüística y a la vez sitio de remanso para su labor misional. Los seminarios de San Martín y San Gregorio fueron en efecto la solución para el aprendizaje y práctica de las lenguas nativas y así estar en la mejor condición para lograr presencia apostólica y social hacia el interior de las comunidades indias. ${ }^{21}$

Por otra parte, recordemos que, en el noviciado de Tepotzotlán, los novicios recibían conocimientos de náhuatl, otomí y mazahua, que, llegado el momento deberían perfeccionar con los misioneros experimentados. ${ }^{22}$ No obstante, con el tiempo, para los padres misioneros, sobre todo, parecía ser lo más recomendable una estancia temporal entre los niños de San Gregorio, con el fin de perfeccionar su dominio del náhuatl o del otomí y así contar con las herramientas óptimas para emprender su labor evangelizadora en las misiones lejanas. Paradójicamente los niños indios, en atención a las eventuales necesidades lingüísticas de los ignacianos, se transforman de educandos en educadores. Como ya se hizo notar, no es difícil imaginar a los catecúmenos corrigiendo a los misioneros en la correcta pronunciación de determinadas voces y a estos últimos inquiriendo a los primeros y tomando nota acerca del significado de esos u otros términos. Esa necesidad e interés de los ignacianos por lograr el dominio de las lenguas indígenas los llevó eventualmente a la preparación de "artes", es decir, gramáticas, vocabularios y diccionarios de las principales lenguas nativas, como los instrumentos ideales y necesarios para lograr ese fin; alcanzado ese propósito y con el apoyo de dichos elementos pedagógicos, se aplicaban posteriormente a la enseñanza de esas lenguas a las nuevas generaciones de jesuitas. ${ }^{23}$ Por otra parte, con el fin de obtener óptimos resultados de

${ }^{20}$ Vargas Ugarte (1963, vol. II, pp. 300-301).

${ }^{21}$ Zubillaga (1974, pp. 13-18).

22 Pérez Alonso (1983, pp. 80-82).

${ }^{23}$ Según Decorme, las principales obras en mexicano de los jesuitas fueron: el Catecismo y Diálogos del padre Tobar, 1573, la Gramática o Arte de la lengua mexicana del padre Antonio del Rincón, México, 1595; Arte de la lengua mexicana con la declaración de los adverbios de ella por el padre Horacio Carochi, rector del Colegio Máximo, México, 1645; él mismo compuso un Catecismo, un Vocabulario y muchas pláticas que se quedaron en la biblioteca del colegio. De la obra del padre Carochi, el padre Ignacio Paredes publicó en el año de 1759 un Compendio del arte de la lengua mexicana, en cuya introducción leemos: "[Compendio] Dispuesto con 
penetración doctrinaria, tanto en la práctica misionera como en la impartición de los servicios religiosos en templos con población indígena, los jesuitas elaboraron catecismos, doctrinas y sermones en las lenguas nativas dominantes. ${ }^{24}$

La actividad lingüística desarrollada por los religiosos, y que tuvo en el seno de San Gregorio uno de sus centros de acción, requería de la existencia en el local de un acervo bibliográfico que pusiese al alcance de los religiosos las herramientas necesarias para la práctica de su labor. Recordemos que Santiago Tlatelolco contó con una biblioteca que, si bien no era muy voluminosa, disponía de los títulos adecuados para sus necesidades. ${ }^{25}$ Tanto los estudios iniciales de Ignacio Osorio como los más recientes de Idalia García Aguilar, entre otros, muestran que la presencia de las bibliotecas en los colegios jesuitas era un asunto indispensable y sus acervos fueron usados de manera constante por miembros de la comunidad. Las Constituciones de la Compañía mandaban, por ejemplo, que cada colegio contase con una "Bibliotheca communis", con los libros necesarios para cubrir las necesidades del plantel. ${ }^{26}$ Más concretamente, en la Ratio studiorum (1586) se recomienda que en todos los colegios existiera una biblioteca y que ésta debía ser de uso común. ${ }^{27}$ Sin embargo, esta disposición estuvo pensada en su origen para los colegios de alumnos europeos. De tal forma que la biblioteca de San Gregorio parecía tener una presencia singular en un plantel dedicado a impartir los rudimentos de las primeras letras a una nómina de niños indígenas que rara vez rebasó los cuarenta alumnos. Al ritmo de esa dinámica se construye en el seno del plantel un fondo bibliográfico cuyo perfil respondía, por partida doble, a los requerimientos de las actividades catequísticas y musicales que allí desarrollaban los ignacianos, pero también a las lingüísticas, tarea que como vemos no era ni con mucho de menor importancia respecto de las primeras.

brevedad, claridad y propiedad por el P. Ignacio Paredes de la misma Compañía, y morador del colegio destinado solamente para indios de San Gregorio de la Compañía de Jesús"; también publicó el Catecismo de Ripalda en lengua mexicana, México, 1758. El padre Nicolás Mercado tenía listo para la imprenta un Arte de la lengua mexicana como se habla en la costa sur de Sinaloa, por el año de 1730. Decorme (1941, t. 1, pp. 253-254). También véase, Los jesuitas y las lenguas indígenas..., pp. 127 (las negritas son nuestras).

${ }^{24}$ Idem.

${ }^{25}$ Véase González González y Gutiérrez Rodríguez (2015), sobre todo el análisis del inventario de la biblioteca.

${ }^{26}$ Osorio Romero (1986, pp. 65).

${ }^{27}$ García Aguilar y Rueda Ramírez (2014, p. 220). 
Si bien no se cuenta hasta el momento con datos que permitan determinar los años en los que la biblioteca de San Gregorio comenzó a funcionar, sí se sabe que para el siglo xvin ésta ya estaba formada y constaba de dos fondos. Uno de ellos, el de acervo más voluminoso, correspondía propiamente a la biblioteca del colegio (común); el otro, más breve, pertenecía a la Cofradía del Señor San José, adscrita ésta a la sede del colegio. Gracias a los inventarios elaborados por los oficiales reales de los haberes del colegio, podemos contar con una relación de los manuscritos y los libros que existían en el mismo. A la Corona interesó que los inventarios de los bienes de la Compañía, incluidos los libros, estuviesen sujetos a normas de elaboración precisas. Aunque ya otros autores la mencionan, conviene recordar que la real cédula de abril 23 de 1767 contiene la "Instrucción de lo que se deberá observar para inventariar los libros y papeles existentes en las casas que han sido de los regulares de la Compañía de todos los dominios de S. M.” Para efectos de inventario, una instrucción adicional, distingue entre los libros del común, es decir, la biblioteca de la Institución y los que resguardaban en sus aposentos los ignacianos. ${ }^{28}$ Independientemente de si los libros se hallaban en la biblioteca común o en los aposentos de los religiosos, éstos tuvieron el hábito de anotar su nombre en la portada o contraportada en aquellos libros de los que hacían uso constante o permanente. ${ }^{29}$

Para el caso de San Gregorio disponemos en la actualidad de tres inventarios: uno correspondiente al año de 1769 , en el que se asientan los documentos e impresos existentes en los aposentos de los religiosos. ${ }^{30} \mathrm{El}$ segundo y tercer inventario corresponden ambos al año de 1774, es decir, siete años después de la expulsión y están compuestos por dos listados: uno en el que se inventarían los libros propiamente del colegio (común) y otro que se corresponde con los considerados como propiedad de la Cofradía de San José. ¿Por qué razón los miembros de la cofradía poseían libros en el colegio? Tratándose de una organización de laicos que, bajo la guía de los jesuitas, trabajaban organizados en torno de las actividades pastorales del templo del colegio - que se hallaba bajo la advocación de la virgen de

${ }^{28}$ García Aguilar y Rueda Ramírez (2014, pp. 222-223).

${ }^{29}$ García Aguilar (2016, pp. 69 y 91).

${ }^{30}$ BNAH, Fondo Colegio de San Gregorio, vol. 121, "Testimonio del quaderno reservado del reconocimiento e Ymbentario de los Libros, Papeles Ympresos, y Manuscritos de confianza que se hallaron en los Aposentos de los Religiosos Jesuitas, asistentes en el Colegio Gregorio de Mexico. Año de 1769". 
Loreto- puede pensarse que los libros servían como fuente de preparación para sus integrantes en las tareas proselitistas y asistenciales que desarrollaban con los habitantes indígenas de los barrios circundantes. Por otra parte, debido a que los miembros de la cofradía tenían vedado el acceso franco al interior del colegio, lo más probable es que ambas bibliotecas ocupasen espacios separados. ${ }^{31}$

\section{Los inventarios de la biblioteca}

El primer inventario de los dos elaborados en el año de 1774, y levantado por Pedro Ramírez de Arispe y José Zerruto, tuvo como fin dar respuesta a la orden dada en la real cédula de 9 de julio de 1769 de separar los fondos de origen los "libros morales y teológicos de los expulsos que contengan doctrinas laxas y peligrosas a las costumbres y a la quietud y subordinación de los pueblos". ${ }^{32}$ La ejecución de la real cédula tuvo como fin depurar y preparar los fondos bibliográficos del colegio para ser reubicados en las bibliotecas de la Universidad y en la del recién reabierto Colegio de San Ildefonso. ${ }^{33}$ En marzo de dicho año, sin embargo, la Dirección de Temporalidades nombra a Francisco Xavier Gamboa comisionado de San Gregorio por muerte del responsable anterior. Con el fin de recibir en orden el colegio y su contenido, Gamboa ordena la elaboración de otro inventario de la biblioteca, ejecutado éste por el comerciante de libros Joseph de Cueto, "vecino de esta ciudad [de México] y con cajoncillo de libros en la Plaza Mayor de ella”. El comisionado Gamboa, quien de inmediato y a diferencia de su antecesor se erige en defensor del patrimonio del colegio, impide que los fondos bibliográficos sean dispersados.

Dado que el inventario de 1769, si bien enlista materiales de interés para nuestro estudio, no es propiamente de la biblioteca del colegio, procederemos a comentar primero los dos que se corresponden con 1774. El

${ }^{31}$ Archivo General de la Nación (en adelante, AGN), Temporalidades, vol. 173, exp. 5, "Año de 1774. Inventario de los papeles y bienes que se hallaron existentes en la Iglesia, capillas y Colegio que fue de Sn. Gregorio de esta ciudad. Fechos de orden del Sr. D. Francisco Xavier Gamboa, del Consejo de su Majestad [...], de que se hizo entrega al Dr. D. Antonio Eugenio Melgarejo". Existe un cuarto inventario correspondiente al año de 1773 y que da fe de las joyas que poseía el colegio al momento de la expulsión, separadas en tres clases. Lleva la misma clasificación que aquí se cita, pero corresponde al número de expediente cuatro.

${ }^{32}$ Citado por Osorio Romero (1986, p. 66).

${ }^{33}$ Como se sabe, San Ildefonso fue también una fundación jesuita. 
primero de ellos, el elaborado por Rodríguez y Zerruto, no es tan detallado como el de Cueto, pero permite tener una idea del conjunto bibliográfico existente en ese momento. Según este documento, la cifra de títulos reunidos en la biblioteca de la Cofradía de San José es de 699 obras. ${ }^{34}$ Observamos que el inventario entregado a Gamboa no enlista los 69 títulos expurgados, pero la merma en la suma total de ambos acervos es apenas notoria, considerando que el número total es de 1664 obras con un total de 3148 volúmenes. Sin embargo, lo que sí muestra el inventario de Rodríguez y Zerruto para los fines del presente trabajo es una interesante relación de impresos relacionados con la mencionada actividad lingüística que los jesuitas llevaban a cabo en San Gregorio, como se podrá apreciar a continuación: ${ }^{35}$

\section{CuAdro 1}

\begin{tabular}{lc}
\hline \multicolumn{1}{c}{ Título } & Número de ejemplares \\
\hline Vocabulario de Molina & 7 \\
Prácticas doctrinales del padre Paredes & 33 \\
Arte de Horacio Carochi & 174 \\
Sermonarios de fray Juan Bautista, León y P. Neigansos & 114 \\
Artes del padre Castel y Carlos Tapia & 14 \\
Manual de administrar sacramentos & 54 \\
Cartilla & 28 \\
\hline
\end{tabular}

Fuente: AGN, Temporalidades, vol. 173, exp. 15-16.

Se trata, en efecto, en su mayoría de impresos de índole catequística y pastoral en los que desempeñan un papel primordial las lenguas indígenas, pues es a los indios a quienes van dirigidos, pero elaborados obviamente por jesuitas peritos en esas lenguas y que al elaborarlos lo hicieron con la intención de dotar de herramientas especializadas - para el mejor conocimiento y dominio de las lenguas nativas- a sus compañeros de la orden. Puede considerarse de esa naturaleza impresos como el Vocabulario de Molina, el Arte o gramática de Horacio Carochi y las de los padres Castel y Carlos Tapia. Muy probablemente por eso estaban depositados en la biblioteca del colegio al tenerlos como materiales de trabajo y estudio.

\footnotetext{
${ }^{34}$ AGN, Temporalidades, vol. 173, exp. 15-16.

${ }^{35}$ Ibidem, f. 79.
} 
El inventario de Cueto es un poco más completo ya que, a diferencia del de Rodríguez y Zerruto, señala lugar y fecha de edición de cada obra. El registro de estos elementos ayuda a precisar los contenidos bibliográficos de los ítems e intentar un desglose más puntual. En primer término, aparecen datos similares en ambos inventarios para lo relativo a los impresos de índole catequística y pastoral en lenguas indígenas señalados arriba, con la única diferencia de que Cueto incluye en esta sección veinte catecismos de la Doctrina del padre Paredes que no se mencionan en el inventario de Rodríguez y Zerruto.

En el caso concreto de los contenidos de la biblioteca del colegio sí existen diferencias notables entre ambos listados. El de Rodríguez y Zerruto registra 896 títulos, en tanto que el de Cueto se reduce a 622. Es comprensible la eventual existencia de una disparidad mínima entre ambos conteos, pero en este caso es por 274 títulos, lo cual lleva a pensar que en el lapso de la elaboración entre uno y otro inventario la biblioteca fue objeto de sustracciones sin control. Se tiene conocimiento, por ejemplo, de que en años anteriores la biblioteca ya había sido objeto de hurtos documentados, como el cometido en el año de 1768 por el soldado del regimiento de la reina Juan Bautista Mendoza. ${ }^{36}$ Amén de estas diferencias escandalosas, la identificación de los temas dominantes en los títulos de la biblioteca deja ver que en realidad éstos tenían muy poco que ver con la educación de dos docenas de niños indios. Si bien la identificación de los temas no fue posible llevarla a cabo de manera muy precisa, en la medida en que muchos de los autores y de los títulos están asentados de manera incompleta o errónea, sí es posible ofrecer un perfil confiable de las materias dominantes, que en términos generales puede expresarse de la siguiente forma:

CuAdro 2

\begin{tabular}{|c|c|}
\hline Temas & Número de ejemplares \\
\hline Teología moral & 258 \\
\hline Homilías & 45 \\
\hline Patrística & 12 \\
\hline Vidas de los santos & 37 \\
\hline Historia e historia sagrada & 25 \\
\hline Biblia, Evangelios & 16 \\
\hline
\end{tabular}


CuAdro 2. Continuación...

\begin{tabular}{lc}
\hline \multicolumn{1}{c}{ Temas } & Número de ejemplares \\
\hline Teología escolástica & 19 \\
Devocionarios & 77 \\
Liturgia y manuales de confesores & 29 \\
Idiomas & 20 \\
Obras de Francisco de Florencia & 5 \\
Jesuitas, ejercicios de san Ignacio y acerca de & 32 \\
Escritos Antigüedad Clásica & 17 \\
\hline
\end{tabular}

FuENTE: Elaboración propia con base en BNAH, Fondo Colegio de San Gregorio, vol. 148, f. 168.

El listado, por lo demás, ofrece algunas notoriedades bibliográficas dignas de llamar la atención y que ponen en evidencia que incluso esta biblioteca del colegio de indios, dotada de un acervo "modesto", registraba títulos importantes de gramática, historia y literatura. Destacan, entre otros, la presencia de un ejemplar de la Biblioteca mexicana de Eguiara y Eguren (1755); ${ }^{37}$ varias obras de fray Luis de Granada; Galateo español de Lucas Gracián (1722); la edición de 1583 de la Gramática de Antonio de Nebrija; la Política indiana de Solórzano y Pereyra; el Teatro americano de fray Agustín de Vetancurt (1698); la Historia de México de Antonio de Solís (1684), y la Historia del Perú del Inca Garcilaso de la Vega, entre otros. Aparte de la sección de obras en lenguas indígenas ya señaladas, existía en este acervo otro tipo de materiales que servían igualmente de apoyo a distintas actividades paralelas llevadas a cabo por los jesuitas en relación con los alumnos indígenas: se trata de la existencia en el listado de cinco libros de coro "viejos”. Recordemos que el inventario se corresponde con el último tercio del siglo XviII, casi en los inicios del clasicismo musical europeo; por lo tanto es muy probable que el llamarlos viejos responda a que hayan estado en desuso por tratarse de libros de obras corales pasadas de moda, y que los "nuevos" - porque al momento de la expulsión el coro y la banda de músicos seguían en funciones-estuviesen permanentemente en el coro del templo o en manos de los cofrades; si bien no se descarta la posibilidad de

${ }^{37}$ De la Torre Villar llevó a cabo un estudio completo y la edición facsímil de la obra de Eguiara y Eguren (1986). 
que se considerasen viejos por el hecho de estar maltratados, con hojas faltantes o rotas, debido al uso constante de los mismos.

Respecto de la cifra de las obras registradas por el inventario de Cueto para la biblioteca de la Cofradía de San José, el documento ofrece un total de 534 obras. Considerando que el listado de Rodríguez y Zerruto comprende 699 obras, observamos una merma de 165 títulos. ${ }^{38}$ Este dato nos indica que la sustracción de libros no sólo se dio en la biblioteca del colegio sino también en la de la cofradía. En lo tocante a los temas dominantes en los contenidos del acervo, el resultado es el siguiente:

CUADro 3

\begin{tabular}{lc}
\hline \multicolumn{1}{c}{ Temas } & Número de ejemplares \\
\hline Teología moral & 132 \\
Homilías, sermones, epístolas, discursos & 29 \\
Patrística & 7 \\
Vidas de los santos & 37 \\
Historia e historia sagrada & 28 \\
Biblia, Evangelios & 20 \\
Liturgia y manuales de confesores & 14 \\
Idiomas & 3 \\
Obras de Francisco de Florencia & 3 \\
Jesuitas, ejercicios de san Ignacio y acerca de & 6 \\
Escritores Antigüedad Clásica & 9 \\
Literatura & 26 \\
Textos apologéticos jesuitas & 13 \\
Catecismos & 7 \\
\hline
\end{tabular}

FUENTE: Elaboración propia con base en AGN, Temporalidades, vol. 173, exp. 15-16.

Aparentemente no existen muchas variantes respecto de los contenidos de la biblioteca del colegio. En ambos acervos dominan, por ejemplo, los textos relativos a homilías y sermones; sin embargo, llama poderosamente la atención la presencia en la biblioteca de la cofradía - como puede observarse en el primer cuadro- de aquellos impresos en lengua náhuatl usados

${ }^{38}$ AGN, Temporalidades, vol. 173, exp. 15-16. 
como materiales catequísticos y de dominio de dicha lengua (vocabularios, sermonarios y cartillas, entre otros). Igualmente es notoria en la misma biblioteca una presencia destacada de obras literarias. Suponemos que, por tratarse del acervo de la Cofradía de San José, para uso preferente de los seglares, sus contenidos se abrían a un abanico temático un poco más amplio. Llama la atención, sobre todo, la calidad de varias de las obras reunidas bajo ese rubro: sor Juana Inés de la Cruz, Obras, edición de 1714; Calderón de la Barca, Autos sacramentales, edición de 1717; Mateo Alemán, Guzmán de Alfarache, edición de 1713; Luis de Góngora, Obras poéticas, edición de 1659; Benito Jerónimo Feijoo, Cartas eruditas, edición de 1736, y de Fénélon, Aventuras de Telémaco, edición de 1733.

Si bien se presume que los contenidos del acervo de la cofradía estaban supervisados por los jesuitas, bien se ve que los cofrades habían desarrollado un marcado interés no sólo por las obras literarias, sino también en torno de los temas históricos, que iba más allá de la mirada teológica de los miembros de la Compañía. Este criterio lo confirma una amplia selección de obras de historia civil y sagrada que proporcionalmente puede considerarse superior a la del acervo del colegio, según se puede apreciar: Louis Moreri, Diccionario histórico, edición de 1753; Antonio Solís, Historia de la conquista de México, edición de 1732 (la obra de Solís se encuentra igualmente en el acervo del colegio); fray Juan de Torquemada, Monarquía indiana, edición de 1723; Juan de Mariana, Historia general de España, edición de 1733; Juan de Solórzano, Política indiana, edición de 1736, y el Catecismo histórico del abate Fleury, edición de 1737. El perfil del contenido de estos títulos revela un interés de los cofrades - de mayoritaria extracción indígena- por la historia local y su relación con la de España, interés que muy probablemente tenía que ver con la inquietud por entender el papel histórico del indígena en la sociedad contemporánea. En suma, de los rubros temáticos registrados para el acervo de la cofradía, sólo el de catecismo puede vincularse directamente con la educación de los alumnos del colegio.

\section{Inventario de los aposentos}

Pongamos ahora nuestra atención en el inventario de 1769. Éste, como se señaló líneas arriba, corresponde a los impresos y manuscritos hallados por los oficiales reales en los aposentos de los jesuitas responsables del colegio, a saber: un rector, un procurador y dos coadjutores. El inventario divide 
los documentos en secciones o grupos temáticos ya se trate de impresos o manuscritos y según su formato - en folio, cuarto, octavo o dieciseisavo-. La relación que hacen los oficiales reales de estos documentos incluye los impresos repetidos que los religiosos "vendían" —según versión de los propios oficiales - o en su defecto distribuían en forma gratuita a todo tipo de catecúmenos que asistían al templo de Loreto y no necesaria o exclusivamente a los niños del colegio. ${ }^{39} \mathrm{El}$ inventario da inicio con el registro de los impresos de marca menor y en folio ubicados en los aposentos del rector de San Gregorio, Ignacio Lizasuain, y de los que ponemos de relieve los relacionados con el manejo de las lenguas nativas: ciento y ochenta y cuatro pliegos o ejemplares de un Catecismo en lengua mexicana, impreso en 1754 en la Imprenta de la Biblioteca Mexicana.$^{40}$ Este catecismo se repartía "graciosamente" entre los indios. Se encuentran dieciséis pliegos y otros tantos ejemplares de una Doctrina del padre Castaño, en idioma castellano y mexicano, impreso en México por Bernardo de Hogal en $1744 .{ }^{41}$ Aparecen ocho pliegos y medio de Oraciones en mexicano a Nuestra Señora de Loreto; de este documento no se señala año de impresión ni casa editora. Se registran otros seis pliegos y medio de las Doctrinas del padre Castaño, impresas en México el año de 1716, en la imprenta de la viuda de Rodríguez Lupersio. $^{42}$ Asimismo figuran dos pliegos de ocho ejemplares de una Instrucción breve en mexicano para confesarse bien; de este documento tampoco se señala pie de imprenta.

En la relación encontramos igualmente otra serie de instrumentos propios para la pastoral y la catequesis: impresos en formato de cuarto, diecisiete sermones, nueve ejemplares de Nuestra Señora de Guadalupe en idioma mexicano, por el padre Paredes, impresos en San Ildefonso. Hay

39 “Testimonios del quaderno...”, BNAH, Fondo Colegio de San Gregorio, vol. 121.

${ }^{40}$ Recordemos que esta imprenta era propiedad de Eguiara y Eguren y la había formado con el fin de publicar su repertorio de autores novohispanos. Véase supra, nota 18.

${ }^{41}$ El impresor Bernardo de Hogal había muerto en el año de 1741 pero le siguió en el negocio su viuda hasta el fallecimiento de ésta en 1755. Medina (1989, t. 1, p. CLXX).

${ }^{42} \mathrm{El}$ hecho de que entre los impresos registrados en el aposento del rector Lizasuain se hallasen dos ediciones de las Doctrinas del padre Bartolomé Castaño indica que el mismo era un instrumento pedagógico de probada eficacia. Otro dato que apunta en esa dirección es el hecho de que las Doctrinas fuesen traducidas al tarasco por el franciscano Ángel Serra hacia finales del siglo XVII. Véase Medina (1989, t. III, p. 306). Medina consigna las Doctrinas como Catecismo, pero ambos con editor y año de edición similares, lo cual nos lleva a pensar que el propio Medina incurrió en error. Por otra parte, José Mariano Beristáin de Souza no registra el impreso en su Biblioteca hispano americana septentrional. 
cinco ejemplares de sermones dedicados también a la virgen de Guadalupe, en castellano, por el padre Orrio, impresos en 1762, en la Imprenta de los Herederos de María Rivera. Se incluyen veintiún cartas edificantes de varios autores, impresas entre 1737 y 1764. En formato de octavo se registran veintiún ejemplares de cartillas o Doctrina en mexicano por el padre Paredes, impresas en la Biblioteca Mexicana, con la anotación "para repartirlas entre los yndios". ${ }^{43}$

En el anterior apartado se mencionan exclusivamente aquellos impresos y manuscritos ubicados en el aposento de padre rector Lizasúain relacionados directamente con el manejo pedagógico y doctrinal de las lenguas indígenas hacia el interior del colegio. Sin embargo, conviene tener presente que la labor del rector tenía que ver igualmente con la administración y la economía del plantel. Por ello, llama la atención, aunque no extraña, que los contenidos de numerosos documentos relacionados con estas actividades estén igualmente redactados en lenguas indígenas. Por ejemplo, en el registro de los documentos del rubro "Ynbentario de Yntereses" de los libros de caxa de folio y quarto, se registra un libro sobre la cofradía o congregación del colegio de San Gregorio denominada de la Annunciata que inicia en 1584 y termina en 1666, "su principio en mexicano". Si bien formalmente esta cofradía se fundó en 1594, es probable que comenzase a funcionar en la fecha que registra el documento y su aprobación por el Ordinario no se liberase hasta el de noventa y cuatro. Que esté redactado en náhuatl posiblemente responde al hecho de que los jesuitas incorporaron a la misma a los niños del colegio, vecinos y familiares indígenas de los contornos, asimismo podría considerarse un condicionamiento de los miembros de la cofradía, con el fin de facilitar la donación de bienes a la misma. ${ }^{44}$ En el rubro "Ynventario cronológico de Ynstrumentos Públicos" también se registran documentos en náhuatl, como es el caso de la "obligación de los yndios de San Sebastián para cantar en San Gregorio los días festivos, en once de enero de [mil] quinientos noventa y tres", indicativo de que después de cuatro años de fundado San Gregorio aun no contaba con coro de niños; una "Certificación en Mexicano sobre veinte y cuatro pesos para misas, dados al Prior fray Alonso de Montemayor"; un resguardo sobre venta de tierras escrito en mexicano de 1690, traducido al castellano en 1734; un "quaderno de foxas quatro sobre fundación del Pueblo de Santiago Tlatelulco, traducida en Mexicano a

43 “Testimonio del quaderno reservado...", BNAH, Fondo Colegio de San Gregorio, vol. 121.

${ }^{44}$ Decorme (1941, vol. 1, p. 309). BNAH, Fondo Colegio de San Gregorio, vol. 121. 
veinte y tres de agosto de 1704"; unas "Diligencias sobre libertarse de Tributos por Caciques, los contenidos en ellas, conforme a pruebas que dieron con Ynstrumentos en Mexicano, de primero de Febrero de [mil] seiscientos cincuenta y cinco"; un testamento en mexicano de doña Antonia Nicolasa, 1716; "un testamento en Mexicano fecho en diez y seis de enero de 1618, traducido al Castellano en 1720".

En el aposento del padre procurador, Joseph de Soldevilla, los oficiales reales inventariaron, entre otras cosas, un ejemplar en octavo de la Doctrina breve sacada del catecismo mexicano, del padre Paredes, reimpreso en la Biblioteca Mexicana; también, en dieciseisavo, un Ochavario de la Concepción y Natividad de María Santísima, en mexicano, impreso en 1758, en la imprenta de Rivera. ${ }^{45}$

En el aposento del padre Martín de Alcocer, se enlistaron los siguientes documentos: medio pliego en folio de un Cathessismo breve en lengua mexicana con el acto de contrición, con licencia en mexicano en la Imprenta de la viuda de Rivera; cuatrocientos ochenta cuadernos de sermones, pláticas, misiones y doctrinas panegíricas y morales, los veinticinco de ellos y cuatro hojas sueltas que están en mexicano; ${ }^{46}$ catorce ejemplares de un Alabado en idioma castellano y mexicano por un padre misionero de la Compañía de Jesús del Colegio de San Xavier (a costa de dicho colegio se imprimió con licencia en el de San Ignacio de la Puebla en el año de 1765); también doscientos noventa y un escritos de fray Bernardino de Sahagún, ${ }^{47}$ los del índice primero y por fray Alonso de Escalona los del segundo índice; todos en mexicano, forrado dicho libro en gamuza; un cuaderno titulado Luz y guía de los ministros evangélicos por fray Baltazar del Castillo; se trata de una explicación de la doctrina cristiana en castellano y en mexicano e impreso en México en $1694 .{ }^{48}$ Igualmente treinta y tres ejemplares del sermón

45 “Testimonio del quaderno reservado...", BNAH, Fondo Colegio de San Gregorio, vol. 121, ff. $81 v$ y 82 . Según el Diccionario de autoridades (1726), Ochavario es lo mismo que Octavario y hacía referencia a la fiesta que se celebraba en los ocho días de una octava, con sermón, música y demás funciones de la Iglesia.

${ }^{46}$ Ibidem, f. 127v.

${ }^{47}$ Puede tratarse de una copia de la Historia general de las cosas de la Nueva España, que hubiesen encargado los jesuitas a los monjes del convento franciscano de Tolosa, Navarra, España, y que usara Carlos María de Bustamante para la edición que llevó a cabo de esa obra en 1823. Acerca del manuscrito de Tolosa y en general de un amplio debate sobre el Códice florentino, véase, D’Olwer y Cline (1973, pp. 186-207).

48 “Testimonio del quaderno reservado...”, BNAH, Fondo Colegio de San Gregorio, vol. 121, f. $131 \mathrm{v}$. 
que en mexicano hizo el padre Paredes a Nuestra Señora de Guadalupe. Asimismo, tres ejemplares de una oración en mexicano a Nuestra Señora de Guadalupe, impresa en México y reimpresa en Puebla (s/a). Un libro en cuarto de sermones y pláticas en lengua mexicana y ejemplos en el mismo idioma, con dos índices, uno al principio que apunta sesenta y nueve sermones y pláticas y otro en el fin que apunta cuarenta y dos ejemplos, todo en trescientas noventa y cuatro fojas. Otro libro con dieciocho sermones y seis ejemplos, todo en ciento trece fojas. Finalmente, cuarenta cuadernos y nueve fojas sueltas, con apuntes en idioma mexicano de pláticas, sermones y doctrinas. ${ }^{49}$ Conviene poner de relieve este último dato, porque permite constatar que el trabajo, dominio y ejercicio lingüístico básicamente en lengua "mexicana" que desarrollaban el rector y los padres coadjutores en el colegio era de carácter permanente. Pláticas y sermones, sobre todo, demandaban constante renovación y las hojas sueltas enunciadas en el inventario así lo ponen en evidencia.

En los aposentos del padre Nicolás Andrés Vázquez se registraron veinticuatro medios pliegos del Catecismo breve de lo que precisamente ha de saber el cristiano, de los cuales hay veinte y cinco ejemplares en castellano y veintitrés en mexicano. También se encontraron tres medios pliegos de María o Catecismo breve en lengua mexicana con el acto de contrición, reimpreso en México en 1754, en la Imprenta de la Biblioteca Mexicana.

\section{Conclusiones}

Como se aprecia por los documentos asentados en los inventarios de las dos bibliotecas, la del colegio propiamente y la de la Cofradía de San José, el perfil de los contenidos de ambas contrasta notoriamente con la actividad central del colegio de educar en las primeras letras, los principios religiosos y la música a una docena de infantes indígenas. En la práctica, San Gregorio funcionaba en forma paralela como una suerte de residencia temporal para religiosos que requerían especializar o afinar su dominio en las lenguas indígenas, luego entonces ambas bibliotecas respondían preferentemente a ese fin, si bien con ligeras variantes. Los títulos que estructuran el acervo de la biblioteca del colegio ponen énfasis en los conocimientos y reflexiones teológicas de los religiosos, en cambio el de la cofradía resguardaba la

${ }^{49}$ Ibidem, f. $136 \mathrm{v}$. 
mayor parte de los textos catequísticos y artes en náhuatl, además de numerosos títulos de llamativa temática histórica y literaria. Esta división nos indica que la biblioteca del colegio funcionaba más como de uso de los religiosos y el de la cofradía se reservaba con mayor asiduidad, para fines de prácticas lingüísticas. Esta percepción se acentúa al revisar los listados de los inventarios de los aposentos, en los que se registran numerosos ejemplares impresos de textos catequísticos impresos en náhuatl, hecho que evidencia que la actividad lingüística desarrollada por los jesuitas en el establecimiento era intensa y se hallaba asociada, además, intrínsecamente, a un trabajo misional que desempeñaba la Compañía en sus fundaciones norteñas. Da la impresión de que San Gregorio y sus pequeños alumnos indígenas - además del desempeño que éstos tenían como coro y conjunto de músicos que engalanaban las funciones litúrgicas de los templos de la ciudad de México- fungían como estación de paso preparatoria de una labor misional de gran envergadura para la que el dominio de las lenguas nativas, principalmente el náhuatl, era factor prioritario. De ello nos habla el registro de cientos de ejemplares de catecismos, sermones, artes, y otros instrumentos catequísticos en idioma Mexicano, existentes en los acervos del colegio y en los aposentos de los religiosos responsables de su manejo. Esos materiales en realidad no estaban pensados para los niños del colegio, al menos no exclusivamente.

Bajo esta óptica cobra sentido la presencia de dos bibliotecas en el colegio, así como el perfil y la calidad de sus acervos. Para los religiosos residentes se requería en el plantel la presencia de las artes o gramáticas requeridas en el estudio y la consulta especializada en el aprendizaje y dominio de las lenguas indígenas, principalmente el náhuatl. Conocimiento demandado, sobre todo, por los visitantes temporales de la orden, y que pernoctaban en San Gregorio con el fin de aprender o perfeccionar el dominio de dichas lenguas, dominio imperativo en el posterior desempeño misional que llevaban a cabo en las misiones jesuitas norteñas. Por otra parte, también eran de utilidad para las actividades proselitistas y asistenciales que desempeñaban los miembros de la cofradía de San José, de cuyos miembros, por lo demás, es innegable su informado gusto literario.

Toda esa actividad reflejada en los papeles de los inventarios quedó trunca con la salida de los ignacianos. La contundencia de la aplicación de la medida habla de una sorpresiva medida política que, sin embargo, era temida ya por los propios jesuitas. En su correspondencia se proyecta el 
grave desasosiego por el que atraviesan meses antes de la aplicación de la real cédula de expulsión, al grado que impresiona a los oficiales reales, y dejándose llevar por el peso del drama de los religiosos, lo dejan asentado en el inventario: en la correspondencia del padre Soldevilla; se lee, "mil noticias funestas escriben otros acerca de los nuestros con su Ylustrísima, enero 27 de 1767"; “ya no veo la hora de ver la vidita tocayo: según todo lo que aparenta me tengo creido que el año de sesenta y siete no lo acabamos con vida, febrero de 1767"; y las obligadas palabras de aliento "No piense vuesa referencia tan funestamente. Yo a lo menos no me persuado que acaben con nosotros, y aun cuando así fuera creo que nos habíamos de gloriar y que todo sería en honra nuestra: podrán cortar, destrozar, pero nunca llegarán a destruir. [...] Lo que sí me persuado, que necesitamos agachar un poco la cabeza, la que acaso teníamos un poco levantada, febrero 16 de 1767 ".

Los ignacianos no agacharon a tiempo la cabeza y hubieron de salir de la Nueva España, lo que significó suspender abruptamente la actividad lingüística que se llevaba a cabo en San Gregorio y ponerlo en riesgo de desaparición. Para su fortuna y gracias a los oficios del comisionado Gamboa, el colegio y su biblioteca se salvaron del cierre definitivo y con el paso de los años ésta última se convirtió, hacia la primera mitad del siglo XIX, en una de las bibliotecas más importantes de la ciudad de México y de la que se beneficiaron autores como Beristáin de Souza, Carlos María de Bustamante, José Fernando Ramírez, Joaquín García Icazbalceta y, por conducto de este último, el historiador estadounidense William H. Prescott.

\section{FUENTES CONSULTADAS}

Archivos

Biblioteca Nacional de Antropología e Historia.

Fondo Colegio de San Gregorio, vol. 121: "Testimonio del quaderno reservado del reconocimiento e Ymbentario de los Libros, Papeles Ympresos, y Manuscritos de confianza que se hallaron en los Aposentos de los Religiosos Jesuitas, asistentes en el Colegio Gregorio de Mexico. Año de 1769”.

Colección Antigua, vol. 254: "Apuntes para la historia del Colegio de San Gregorio por Faustino Galicia Chimalpopoca”. 
Archivo General de la Nación.

Temporalidades, vol. 173, exp. 5: “Año de 1774. Inventario de los papeles y bienes que se hallaron existentes en la Iglesia, capillas y Colegio que fue de Sn. Gregorio de esta ciudad. Fechos de orden del Sr. D. Francisco Xavier Gamboa, del Consejo de su Majestad [...], de que se hizo entrega al Dr. D. Antonio Eugenio Melgarejo".

Archivo Histórico de Hacienda, leg. 281-29.

\section{Bibliografía}

Acosta, J. de (1954). Obras. Est. prel. de Francisco Mateos. Madrid: Atlas (Biblioteca de Autores Españoles, 73).

Alegre, F. J. (1956). Historia de la provincia de la Compañía de Jesús de Nueva España (vol. II). Ed. de E. J. Burrus y F. Zubillaga. Roma: Institum Historicum Societatis Iesu.

Astrain, A. (1905-1925). Historia de la Compañía de Jesús en la Asistencia de España. Madrid: Razón y Fe (7 tomos).

Concilio III Provincial Mexicano, celebrado en México el año 1585 (1870). Publicado por Mariano Galván Rivera. Barcelona: Imprenta de Manuel Miró y D. Marsá.

Decorme, G. (1941). La obra de los jesuitas mexicanos durante la época colonial (t. 1). México: Robredo.

D’Olwer, L. N., y H. Cline (1973). Bernardino de Sahagún, 1499-1590. Handbook of Middle American Indians. Guide to Ethnohistorical Sources, University of Texas Press, Austin, 13, 186-207.

Diccionario de autoridades (2002). Ed. facsímil de la de 1726. Madrid: Gredos (3 tomos).

Eguiara y Eguren, J. J. (1986). Biblioteca mexicana. Edición de Ernesto de la Torre Villar. México: Universidad Nacional Autónoma de México (5 tomos).

GARCía Aguilar, Idalia (2014). Imprenta y librería jesuitas en la Nueva España. En I. García Aguilar y P. Rueda Ramírez (coord.), El libro en circulación en la América colonial. Producción, circuito de distribución y conformación de bibliotecas en los siglos XVI al XVIII (pp. 205-237). México: Quivira.

(2016). Entre el olvido y la supervivencia. Los libros jesuitas del colegio de San Luis. Revista de El Colegio de San Luis, 11, 48-105.

GonzÁlez GonzÁlez, E. (2015). En busca de la universidad. Santo Domingo, México y Lima en el siglo xvir. Universidades, año LXV, 65, julio-septiembre, 23-40. 
(2011). Los usos de la cultura escrita en el Nuevo Mundo. El Colegio de Tlatelolco para indios principales (siglo xvI). Estudis. Revista de Historia Moderna, Valencia, 37, 91-110.

GonzÁlez González, E. y V. Gutiérrez Rodríguez (2015). Una biblioteca de latinidad para indios caciques: Santa Cruz de Tlatelolco (México, s. XVI). En Università e formazione dei ceti dirigenti, per Gian Paolo Brizzi, pellegrino dei saperi (pp. 199-224). A cargo de G. Angelozzi, M. T. Guerrini, G. Olmi. Bolonia: Bononia University Press.

Historia general de la Compañía de Jesús en la Provincia del Perú. Crónica anónima de 1600 [...] (1944). Ed. prep. por F. Mateos. Madrid: Consejo Superior de Investigaciones Científicas (2 vols.).

Los jesuitas y las lenguas indígenas de México (1927). Anales del Museo Nacional de Arqueología, Historia y Etnografía, México, 4a. época, v, 97-156.

Medina, J. T. (1989). La imprenta en México (1539-1821). Ed. facsímil. México: Universidad Nacional Autónoma de México (t. 1).

Menegus, M. (2004). El Colegio de San Carlos Borromeo. En H. Casanova y C. Lozano (ed.), Educación, universidad y sociedad: el vínculo crítico (pp. 283-301). Barcelona: Universidad de Barcelona/Universidad Nacional Autónoma de México (en la versión digital, enero de 2019).

Menegus, M., y R. Aguirre (2006). Los indios, el sacerdocio y la universidad en Nueva España, siglos XVI-XVIII. México: Plaza y Valdés.

Osorio Romero, I. (1986). Historia de las bibliotecas novohispanas, México, Secretaría de Educación Pública, Dirección General de Bibliotecas.

PÉrez Alonso, M. (1983). Tepotzotlán, centro de irradiación cultural. Historiae Variae, Universidad Iberoamericana, 1, 89-104.

(1988). Los jesuitas en Tepotzotlán. En Tepotzotlán. La vida y la obra en la Nueva España (pp. 80-89). México: Museo Nacional del Virreinato.

PÉrez de Ribas, A. (1992). Historia de los triumphos de nuestra santa fee. Edición facsímil de la de 1645. Introd., notas y apéndices de I. Guzmán Betancourt. México: Siglo XXI.

Ramírez, F. (1552-1630) (1987). El antiguo colegio de Pátzcuaro. Est., ed., notas y apéndice de G. Viveros. Michoacán: El Colegio de Michoacán/Gobierno del Estado de Michoacán.

Soberón Mora, A. (2005). ¿ Evangelizadores o catedráticos de indios? Los colegios jesuitas del Cercado de Lima y de San Gregorio de México para indios caciques, siglos XVII-XVIII. Anuario de Estudios Bolivianos, Archivísticos y Bibliográficos, 11, 563-583 (Ediciones Archivo y Biblioteca Nacionales de Bolivia, Sucre).

(2008). San Gregorio, un colegio transcolonial: de la catequesis jesuita para infantes caciques, a la pedagogía liberal de Juan Rodríguez Puebla. Tesis de doctorado, Escuela Nacional de Antropología e Historia. 
Vargas Ugarte, R., S. J. (1963). Historia de la Compañía de Jesús en el Perú. Burgos (4 vols.).

Venegas, M., S. J. (1979). Obras californianas del padre [...]. Edición y estudios de W. M. Mathes, bibliografía e índices de V. C. Fisher y M. Coronado. La Paz: Universidad Autónoma de Baja California Sur (5 vols.).

Zubillaga, F. (1974). Las lenguas indígenas de Nueva España en la actividad jesuita del siglo XVI. Caracas: Universidad Católica "Andrés Bello".

\section{SOBRE EL AUTOR}

Doctor en Historia y Etnohistoria por la Escuela Nacional de Antropología e Historia. Actualmente es investigador de la Dirección de Estudios Históricos del INAH, y fue su director de 2008 a 2010. Miembro fundador y posterior director de la revista Dimensión Antropológica. Participa en el Consejo de Asesores de la revista Relatos e Historias en México. Desde 2010 hasta la edición presente es integrante del jurado del premio Atanasio G. Saravia de Historia Regional, Banamex. Ha publicado en coautoría Mapas y planos antiguos de Colima y el Occidente de México, 1521-1904 (Consorcio Minero Peña Colorada, 1978); La correspondencia mexicana de William H. Prescott, 1838-1856 (Consejo Nacional para la Cultura y las Artes, 2001); El patrimonio cultural en América. Tomo I. Investigación y educación patrimonial (2012) y El patrimonio cultural en América. Tomo II. Conservación y uso social (2014). 